\title{
Espaços arquitetônicos dos internatos em Sergipe
}

\author{
Architectural spaces of boarding institutions in Sergipe
}

Joaquim Tavares da Conceição ${ }^{1}$

\begin{abstract}
Resumo
Este artigo apresenta uma compreensão histórica a respeito das disposições de prédios adaptados e planejados para os serviços do internato escolar, localizados em Sergipe, na primeira metade do século XX. O estudo problematiza os tipos adotados e as condições higiênicas desses espaços. $\mathrm{O}$ trabalho se enquadra no campo da história da educação, especificamente entre os estudos que buscam compreender os significados do espaço e da arquitetura escolares e interpretam o espaço escolar como parte integrante do currículo e/ou relacionam a temática com o discurso higienista. O prédio do Colégio N. Sra. de Lourdes foi o primeiro edifício originalmente projetado e construído para servir às funções de colégio-internato feminino. O edifício, construído em dois pavimentos, possuía as principais divisões indicadas para o funcionamento de um internato (dormitórios, refeitório, rouparia, instalações sanitárias, cozinha, copa, despensa). Esse modelo de prédio escolar representou a concretização do ideal higiênico pedagógico de um edificio especialmente projetado e construído para o funcionamento de colégio-internato. Por outro lado, o Colégio Tobias Barreto é exemplo de internato funcionando em espaços adaptados. O colégio ocupou casas e/ou sobrados residenciais alugados, de construção antiga, localizados em diferentes pontos no centro da cidade. As instalações para os serviços do internato (dormitórios, refeitório, rouparia e instalações sanitárias) estavam adaptadas em diferentes espaços de um conjunto de casas ocupadas pelo colégio. As adaptações nos prédios para as dependências de internato quase sempre relegavam os preceitos de higiene às conveniências econômicas do estabelecimento.
\end{abstract}

Palavras-chave: Espaços escolares. História da Educação. Internatos. Sergipe.

\footnotetext{
${ }^{1}$ Doutor em História (2012) pelo Programa de Pós-Graduação em História da Universidade Federal da Bahia, Mestre em Educação (2007). Professor efetivo da Universidade Federal de Sergipe com atuação no Colégio de Aplicação, no Programa de Pós-Graduação em Educação (PPGED-UFS) e no Programa de Mestrado Profissional em Ensino de História (Prof HistóriaUFS). Líder do GRUPO DE ESTUDOS E PESQUISAS EM HISTÓRIA DA EDUCAÇÃO: Memórias, sujeitos, saberes e práticas educativas (GEPHED/CNPq/UFS). Avaliador do Programa Nacional do Livro Didático - PNLD 2016: História: Ensino Fundamental anos iniciais, PNLD 2018: História: Ensino Médio. Coordenador do Centro de Pesquisa Documentação e Memória do Colégio de Aplicação (UFS). Sócio efetivo do Instituto Histórico e Geográfico de Sergipe. Membro do corpo editorial da Revista Tempos e Espaços em Educação, Membro do Conselho Editorial da Universidade Federal de Sergipe e Editor da Revista do Instituto Histórico e Geográfico de Sergipe.
}

Interfaces da Educ., Paranaíba, v.11, n.31, p. 68-92, 2020

ISSN 2177-7691 


\section{Abstract}

This article is a historical understanding about the disposition of adapted and planned buildings for the boarding school services, located in Sergipe, in the first half of the twentieth century. The study discusses the adopted types and the hygiene conditions of these spaces. The work is placed in the field of history of education, specifically among the studies that try to understand the meanings of space and school architecture and interpret the school as part of the curriculum and/ or relate the subject with the hygienist discourse. The building of N. Sra. De Lourdes School was the first building originally designed and built to serve for boarding functions of the girls' boarding school. The building, built on two floors, had the major divisions indicated for the operation of a boarding school (dormitories, dining hall, linen closet, toilets, kitchen, butler's pantry, utility room). This model of school building represented the execution of the hygienic pedagogical ideal of a building specially designed and built for the boarding school operation. On the other hand, Tobias Barreto School is an example of boarding institution running in adapted spaces. The school occupied houses and/ or rented residential houses, of old building, located at different points in downtown. The installations for boarding services (dormitories, dining hall, linen closet and toilets) were adapted in different spaces of a set of houses occupied by the school. Adaptations in the buildings for boarding dependencies almost always relegated the hygiene requirements to economic property amenities.

Keywords: Architectural spaces. Education History. Boarding Schools. Sergipe.

\section{Introdução}

Os estudos que buscam compreender os significados do espaço e da arquitetura escolar apresentam uma produção importante e significativa no campo da história da educação. De maneira geral, são produções que discutem as concepções funcionais e simbólicas do espaço escolar e relacionam a temática com questões pedagógicas e/ou higiênicas (BENCOSTA, 2019). Seguindo esse eixo de pesquisa, este artigo apresenta uma inovação ao direcionar o interesse de análise de forma específica para os espaços dos internatos. Nesse intuito, tomando como recorte a cidade de Aracaju na primeira metade do século XX, o estudo elucida características de prédios adaptados, adotando como arquétipo a conformação das instalações físicas do internato do Colégio Tobias Barreto, e, o modelo de edificio originalmente projetado para servir como internato, observando a configuração do edifício-internato do Colégio Nossa Senhora de Lourdes. 
No estado de Sergipe, na primeira metade do século XX, a maioria dos internatos, estava instalada em casas residenciais ou em prédios adaptados para o funcionamento de colégios-internatos (CONCEIÇÃO, 2012). Tanto na capital Aracaju, como nas cidades de maior desenvolvimento econômico, antigos sobrados residenciais tiveram seus cômodos adaptados para servirem como salões de aula e dormitórios para os alunos pensionistas. As casas que abrigavam os pequenos internatos, em regra, possuiam um salão de aulas de pequenas proporções e um ou dois quartos que funcionavam como dormitórios para os poucos alunos pensionistas (internos), garantindo uma renda extra ao proprietário do estabelecimento.

A propósito do tipo de internato "familiar", o escritor sergipano Gilberto Amado, interno em um colégio de Aracaju na passagem do século XIX para o século XX, registrou sua impressão sobre esse tipo de estabelecimento:

\begin{abstract}
Colégio interno em Aracaju, Colégio Oliveira, único aliás no Estado, tinha internato, no sentido normal do termo, apenas no nome. Era uma casa chata de muitas janelas, junto do quartel, numa esquina no fim da rua da Frente, no caminho da Fundição. [...] Quando entrei, o colégio estava cheio; quartos atulhados de camas juntas. Os meninos corriam por cima delas sem ter que pular no tijolo. Um criado velho, de semana em semana, passava a vassoura por debaixo, mas só arrebanhava o sujo das beiradas; o do meio ficava. De noite subia do chão um cheiro de poeira molhada, um ranço de bolor velho (AMADO, 1999, p. 162).
\end{abstract}

Os principais colégios-internatos que existiam em Sergipe na primeira metade do século XX, Tobias Barreto, Grêmio Escolar e Jackson de Figueiredo, embora congregassem muitos alunos pensionistas, ofereceram o espaço do internato e todas as dependências do estabelecimento resultando de adaptações de prédios assobradados. As edificações escolares originalmente planejadas, com dependências privativas para o internato, foram um empreendimento que somente os colégios católicos instalados em Sergipe tiveram condições de concretizar. Os primeiros foram, em Aracaju, os colégios N. Sra. de Lourdes das Irmãs Sacramentinas, Salesiano N. Sra. Auxiliadora e Patrocínio São José, e na cidade de Propriá, o Colégio Nossa Senhora das Graças. A figura 1 apresenta as linhas modernas do prédio 
planejado para funcionar como internato do Colégio Patrocínio de São José, ' fundado pela Congregação das Irmãs Franciscanas Hospitaleiras da Imaculada Conceição, edificado no ano de 1945 em Aracaju.

Figura 1. Prédio do Colégio Patrocínio São José - Praça Tobias Barreto (Aracaju).

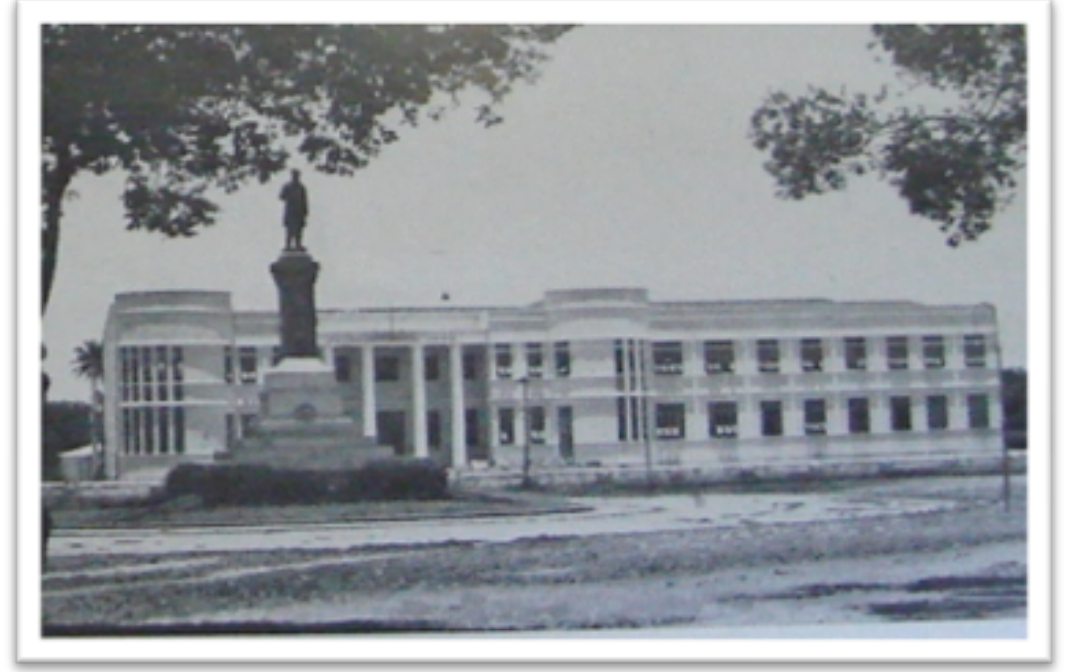

Fonte. BRASIL. Instituto Brasileiro de Geografia e Estatística. Sinopse Estatística do Municipio de Aracaju. Rio de Janeiro: IBGE, 1951.

Nas primeiras décadas do século XX o discurso higienista a respeito de condições adequadas para a instalação e acomodações de internatos escolares estava presente nos congressos sobre educação e em alguns tratados, compêndios ou manuais de pedagogia. A esse respeito, é elucidativa a tese apresentada na I Conferência Nacional da Educação, realizada em Curitiba, em 1927, intitulada "A Higiene nos internatos: estudo das condições sanitárias dos internatos de São Paulo", apresentada pelo médico Eurico Branco Ribeiro (RIBEIRO, 1997). Esse trabalho foi resultante de uma inspeção realizada pelo autor, no ano de 1926, em 10 colégiosinternatos particulares da cidade de São Paulo. Como informa o próprio título da tese, a higiene foi o eixo principal para a análise dos internatos. A partir desse enfoque o autor apresenta e analisa diversas recomendações para o funcionamento higiênico de um internato. Suas observações e contribuições recaíam sobre as condições físicas do internato (localização e disposição geral, o edifício escolar e suas divisões), a respeito das condições de atendimento e ingresso dos internos (assistência médica e dentária, profilaxia, contatos entre internos e externos, enxoval) e a organização Interfaces da Educ., Paranaíba, v.11, n.31, p. 68-92, 2020 
propriamente pedagógica dos internatos (horários, o ensino de higiene e a educação sexual).

O médico Eurico Branco Ribeiro apresentava como ideal para o funcionamento adequado de um internato um prédio completamente isolado de outros edificios, com boa disposição e com bastante arvoredo. Sobre esse aspecto ele concluiu que não existiam essas condições para todos os internatos pesquisados, os edifícios dos colégios pesquisados funcionavam em prédios especialmente construídos para servirem como colégio-internato e em prédios adaptados para essa função. Embora os primeiros apresentassem melhores condições sanitárias, todos padeciam de falhas que deveriam ser corrigidas a fim de se adaptarem aos novos preceitos higiênicos (RIBEIRO, 1997).

Igualmente, no início do século XX, precisamente no ano de 1912, o médico Vieira de Mello, encarregado do "Serviço de Inspeção Médico Sanitário das Escolas de São Paulo", organizou um conjunto de preceitos higiênicos que deveriam ser observados para a instalação de um internato. Repetindo as prescrições expressas em recomendações higiênicas para os internatos que circulavam na época, o autor dividiu suas orientações em três pontos: situação e orientação do edificio, o edificio e suas dependências e higiene dos colegiais (MELLO, 1912).

Logo, dominavam nas discussões sobre os espaços dos internatos aspectos relacionados às condições higiênicas e disposições das acomodações e, quase sempre, baseadas na circulação de ideias estrangeiras. Um impresso alemão de autoria do médico Leo Burgerstein, traduzido para o português, exemplifica essa situação. $O$ autor alemão apresenta diversos aspectos da higiene escolar e dentro dessa temática apresenta os inconvenientes dos internatos pela facilidade da propagação das enfermidades contagiosas, devido ao grande contingente de pessoas compartilhando o mesmo espaço, e, segundo ele, pela frequência como eram difundidos os "desvios sexuais". Para o autor, o modelo mais recomendado era o dos semi-internatos, edificados nas imediações da cidade. Nesse modelo o estudante poderia passar o dia na escola e a noite em casa com a família. A vantagem do semi-internato, segundo o autor, estava no menor Interfaces da Educ., Paranaíba, v.11, n.31, p. 68-92, 2020 
gasto com relação ao internato e porque o estudante podia continuar sob a influência educativa da família (BURGERSTEIN, 1934).

\section{Espaços adaptados: o internato do Colégio Tobias Barreto}

O internato do Colégio Tobias Barreto é um exemplo bastante elucidativo de como prédios, originalmente construídos para servir como residência familiar, eram adaptados para funcionar como internato dormitório, refeitório, cozinha, instalações sanitárias, rouparia, enfermaria a fim de receber um grande número de alunos internos. O Colégio Tobias Barreto foi um colégio-internato particular que, embora tenha chegado a congregar mais de 100 pensionistas do sexo masculino, sempre funcionou em espaços adaptados para os serviços do internato. Fundado no ano de 1909 na cidade de Estância, interior do estado de Sergipe, pelo professordiretor José de Alencar Cardoso ${ }^{2}$ (ESTATUTOS do..., 1911, p. 3), foi transferido para a capital Aracaju em 1913, funcionando como internato e semi-internato masculino e externato misto.

No sistema de "classificação escolar" (BOURDIEU, 2010) o estabelecimento gozava de amplo prestígio social adquirido pelo grande contingente de alunos egressos do colégio que se formavam nas escolas superiores do país nos cursos de medicina, engenharia, direito e em academias militares (FREIRE, 1933) e assumiam posições de destaque na burocracia estatal e em profissões liberais. Além disso, o colégio contava com um prestigiado corpo de professores do principal colégio secundário público estadual, o Ateneu Sergipense (SERGIPE, 1938).

No ano de 1935 as matrículas alcançaram no curso primário 329 alunos (289 masculinos, 40 femininos) e no curso secundário 248, sendo 209 masculinos e 39 femininos (GUIMARÃES, 1936). No final da década de 1940 as matrículas no estabelecimento já ultrapassavam mais de 600 alunos nos diferentes níveis de ensino oferecidos. O aumento do número das

\footnotetext{
2 José de Alencar Cardoso nasceu na cidade de Estância em 18 de abril de 1878, filho do professor Severino Cardoso, e de Maria Antonia Cardoso. Após a conclusão dos preparatórios no Colégio Ateneu Sergipense, ingressou na Escola Militar da Praia Vermelha (RJ). Retornando a Sergipe, fundou o Colégio Tobias Barreto e exerceu diversos cargos públicos. MANGUEIRA, Francisco Igor de Oliveira. Colégio Tobias Barreto: escola ou quartel? (1909-1946). 2003. Dissertação (Mestrado em Educação) - Universidade Federal de Sergipe, São Cristóvão, SE, 2003.
} 
matrículas gerais também foi acompanhado pelo aumento do número de alunos na condição de internos, chegando a mais de 100 pensionistas no final de 1940.

Uma particularidade do Colégio Tobias Barreto era o funcionamento na instituição de uma escola de instrução pré-militar, tendo como instrutores oficiais do Exército Brasileiro (FREIRE, 1933). O engajamento no "batalhão escolar" era obrigatório para todos os alunos maiores de 15 anos (COLÉGIO, 1936). Nele, os alunos participavam das escalas de serviço, manejo de fuzis, exercícios físicos e submetiam-se a uma hierarquia e disciplina militares. Para isso, os alunos recebiam treinamento e trajavam uniforme militar nas atividades internas e nas solenidades cívicas externas (MANGUEIRA, 2003).

O internato do Colégio Tobias Barreto ocupou casas e/ou sobrados residenciais, localizados em duas quadras no centro da cidade, próximos uns dos outros, com adaptações para a instalações de espaços específicos de internamento. Essas casas foram construídas, originalmente, para residência familiar, e mesmo as modificações visando à adaptação dos prédios para a finalidade escolar não lhes modificaram substancialmente o destino original de residência (SANTANA, 1943). A localização das duas principais casas ocupadas pelo colégio, edificios 1 e 2 (Figuras 2 e 3), era considerada salubre, pois os prédios estavam orientados frente à nascente, considerando como satisfatórias as condições de insolação e distribuição da luz solar. Além disso, as ruas eram pavimentadas com pedras, de pouco tráfego, sem ruídos e de fácil acesso, podendo se chegar de qualquer ponto da cidade com facilidade, de bonde ou a pé. O entorno dessas casas ocupadas pelo colégio era formado por residências de famílias ricas (FREIRE, 1933). 
Figura 2. Edifício 1 do Colégio Tobias Barreto (Aracaju).

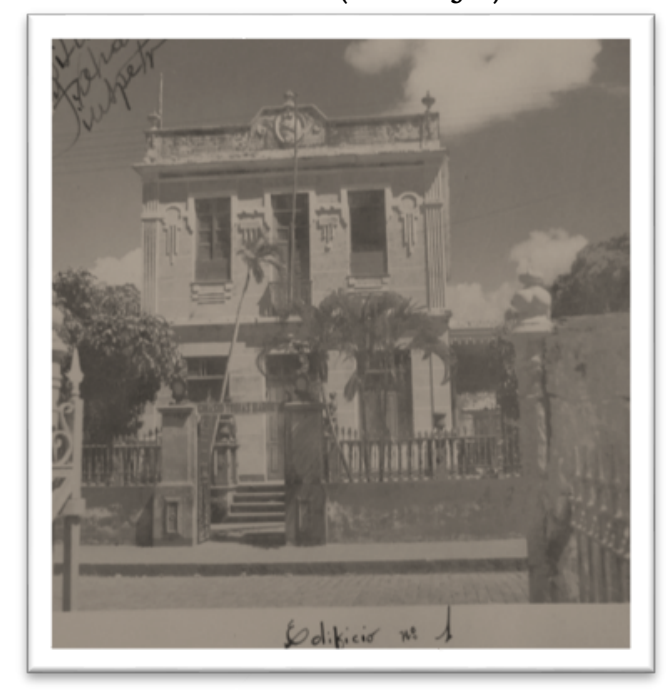

Fonte. SANTANA, 1943.
Figura 3. Edificio 2 do Colégio Tobias Barreto (Aracaju).

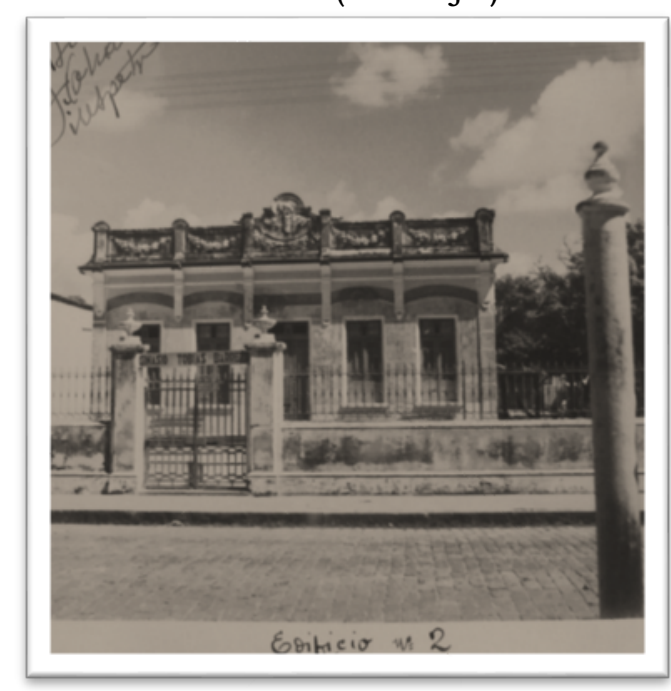

Fonte. SANTANA, 1943.

Os edifícios 1 e 2 (Figuras 2 e 3) eram contíguos, existindo entre eles um espaço de 18,30m e achavam-se afastados das casas vizinhas de 5,60m o primeiro e $8,10 \mathrm{~m}$ o segundo. O primeiro estava recuado da rua $11,80 \mathrm{~m}$ e o segundo, 4,30m. Uma das casas ocupadas pelo colégio, edificio 1 (Figura 2), tinha dois pavimentos no primeiro corpo, medindo $272,80 \mathrm{~m}^{2}$, ambos soalhados e forrados, completamente isolados e contornados por varandas cobertas, e o segundo corpo tinha um só pavimento com a dimensão de $118,08 \mathrm{~m}^{2}$. O esquema do edificio 1 (figura 4) apresenta as divisões internas do andar térreo e superior: dormitório dos maiores (1), dormitório dos médios (2), dormitório dos menores (3), escada (4), instalações sanitárias (5), sala de aula (6), portaria (7), varanda (8) e tanque de água (9). Ao lado esquerdo desse prédio existiam pequenas construções que funcionavam como instalações sanitárias femininas (9), rouparia (10), tanque de água (11) e varanda (12).

Figura 4. Esquema 1- Edificio 1 do Colégio Tobias Barreto. 


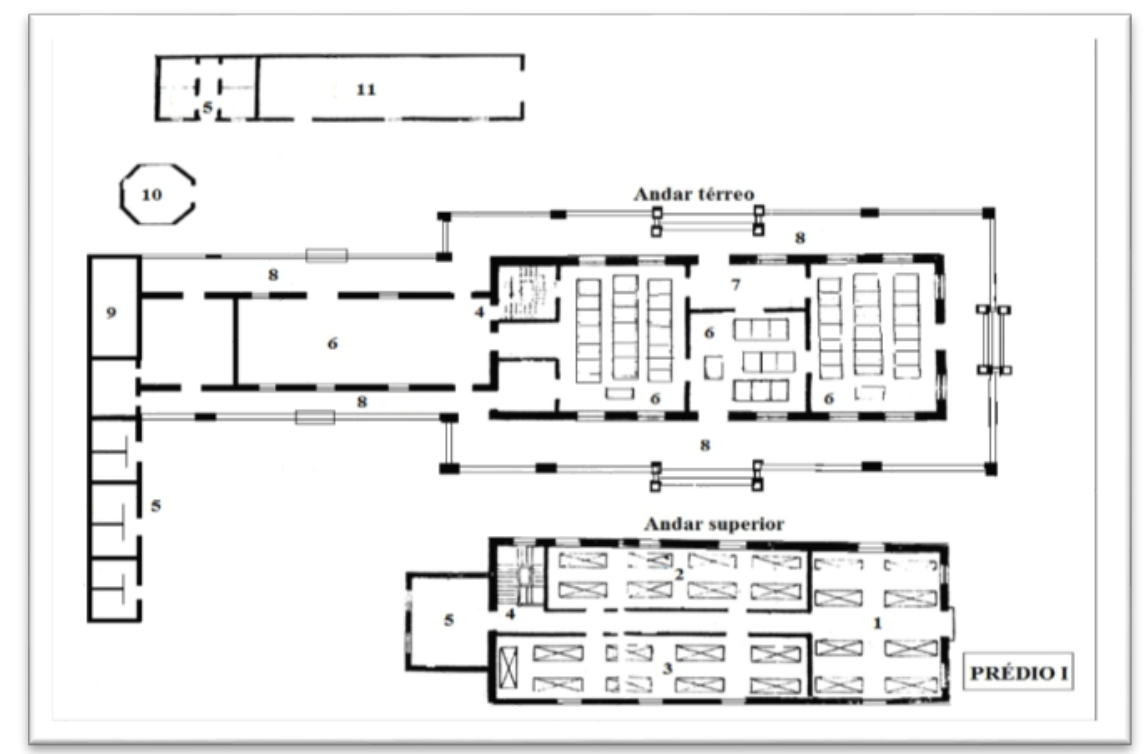

Fonte. Esquema elaborado pelo autor conforme COLÉGIO Tobias Barreto. Planta do Colégio Tobias Barreto. Prédios 1 e 2. Aracaju, DIES - Arquivo de Escolas Extintas, [193?].

A outra casa utilizada pelo Colégio Tobias Barreto, edifício 2, (Figura 3) tinha apenas um pavimento, em dois corpos, medindo o primeiro corpo $237,12 \mathrm{~m}^{2}$, e o segundo, $123,60 \mathrm{~m}$ (SAMPAIO, 1946). Nela estavam instaladas as seguintes dependências (Figura 5): gabinete de física, química e história natural (1), sala de aula (2), sala de ciências físicas e naturais (3), sala dos professores e administração (4), biblioteca (5), refeitório (6), copa (7), cozinha (8), dispensa (9) e instalações sanitárias (10).

Figura 5. Esquema 2 - Edifício 2 do Colégio Tobias Barreto.

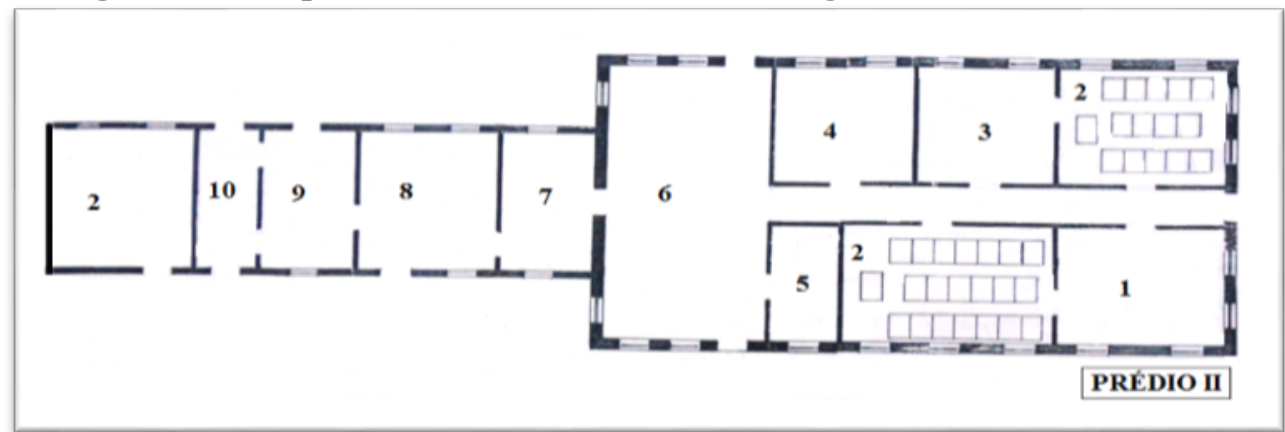

Fonte. Esquema elaborado pelo autor conforme COLÉGIO Tobias Barreto. Planta do Colégio Tobias Barreto. Prédios 1 e 2. Aracaju, DIES Arquivo de Escolas Extintas, [193?].

A fim de atender à crescente demanda, no decorrer da década de 1940 o colégio ampliou o espaço ocupado, servindo-se de outras casas residenciais Interfaces da Educ., Paranaíba, v.11, n.31, p. 68-92, 2020 
alugadas, localizadas próximo às duas casas principais do colégio, as quais estavam situadas na mesma rua e defronte aos edificios 1 e 2 . Tratava-se de um chalé conjugado, edificio 3 (Figura 6), onde estavam instaladas seis salas de aulas, e metade de outro chalé conjugado, edifício 4, (Figura 7), vizinho a este, utilizado para dormitório dos alunos menores.

Figura 6. Edifício 3 do Colégio Tobias Barreto.

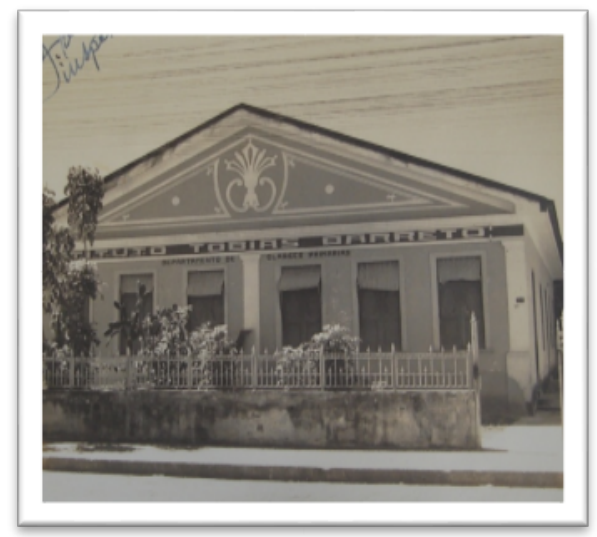

Fonte. SANTANA, 1943.
Figura 7. Edificio 4 do Colégio Tobias Barreto.

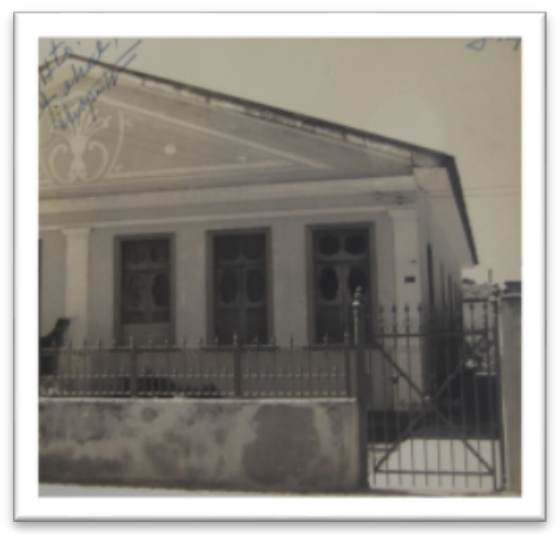

Fonte. SANTANA, 1943.

O Colégio Tobias Barreto também ocupou outras casas residenciais como dependências ou anexos para o internato. Em sequência, a imagem apresenta uma dessas casas em rua próxima onde estavam localizadas as casas principais ocupadas pelo colégio.

Figura 8. Fachada de casa ocupada pelo Colégio Tobias Barreto na Rua de Estância, Aracaju.

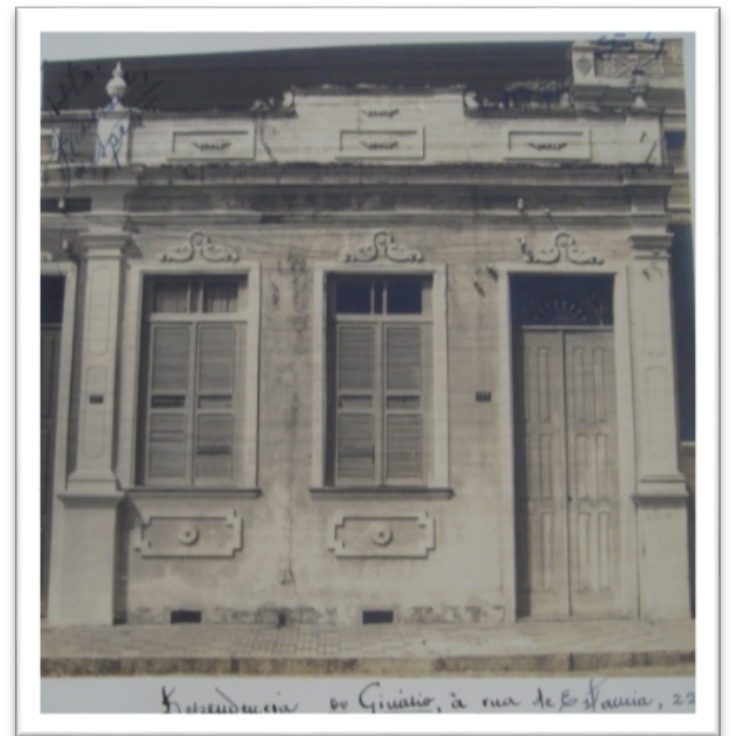

Fonte. SANTANA, 1943.

Interfaces da Educ., Paranaíba, v.11, n.31, p. 68-92, 2020 
Nas inspeções realizadas no colégio pelo Serviço de Inspeção Federal do Ministério da Educação, na década de 1930, o fato de o estabelecimento funcionar em diferentes casas residenciais, ainda que com certas adaptações para servirem como espaços para estabelecimento escolar, foi um dos fatores que contribuíram para a classificação insuficiente ou no máximo regular do colégio (GUIMARÃES, 1936). Nessas inspeções era utilizada uma ficha de avaliação, denominada de "Ficha de Classificação Suplementar dos Estabelecimentos de Ensino Secundário", contendo os seguintes itens referentes às condições das instalações e espaços do internato: refeitório (área, iluminação e ventilação, mobiliário e outro material, lavatórios); copa (pavimentação, revestimento das paredes, instalação para lavagens de louça, mesas e outros materiais); cozinha (pavimentação, revestimento das paredes, iluminação e ventilação, localização, instalações, armários e material de cozinha); despensa (pavimentação e revestimento das paredes, iluminação e ventilação, armários); dormitórios (área, iluminação e ventilação, localização e mobiliário), instalações higiênicas (lavatórios, chuveiros, water closets, bidês); enfermaria (pavimentação, revestimento das paredes, condições de isolamento e material e instalações) e instalações diversas - rouparia, lavanderia, farmácia e gabinete dentário).

Segundo os relatórios de inspeção, os prédios utilizados pelo Colégio Tobias Barreto rigorosamente não atendiam às normas pedagógicas modernas, apesar das adaptações realizadas, como ressaltava o inspetor Hernane Mesquita Prata em seu relatório de inspeção: "[...] as adaptações de prédios escolares, por melhor que sejam feitas, quase sempre não corrigem, nem podiam corrigir certas características marcantes da construção adaptada" (PRATA, 1953). Todavia, ressaltava que mesmo assim as exigências mais indispensáveis prescritas pela higiene escolar, como a proporcionalidade entre área e lotação, condições de iluminação e ventilação, tinham sido atendidas pelo estabelecimento.

As instalações para os serviços do internato (dormitórios, refeitório, rouparia e instalações sanitárias) estavam adaptadas em diferentes espaços dos edifícios 1 e 2 (Figuras 2 e 3 ) ocupados pelo estabelecimento. No início 
da década de 1930 o colégio utilizava como dormitório todo o pavimento superior do edificio 1, subdividido em três compartimentos (dormitórios), providos de banheiros, sanitários e lavatórios coletivos. O primeiro dormitório era dos pensionistas maiores, com $37,44 \mathrm{~m}^{2}$, com a colocação de oito camas; o segundo dormitório era dos médios com $37,50 \mathrm{~m}^{2}$, com nove camas e o dormitório dos menores medindo $30,90 \mathrm{~m}^{2}$ e a colocação de oito camas. Todos esses compartimentos-dormitórios estavam em desacordo com a legislação sanitária da época, que determinava a superficie mínima de $6 \mathrm{~m}^{2}$ por pessoa ou leito (SERGIPE, 1937).

Os dormitórios eram providos de camas feitas de ferro e madeira (modelo patente), com colchões e travesseiros de capim, providas de mesinhas de cabeceira. Existia também uma rouparia instalada em uma pequena construção avulsa, ao lado do edifício 1. O refeitório, copa, cozinha e despensa estavam instalados no edifício 2 .

Em 1938 o internato do Colégio Tobias Barreto chegou a congregar mais ou menos 100 alunos internos, o que determinou, na década seguinte, a realização de ampliações, reformas e adaptações nos dormitórios, rouparia refeitório e instalações sanitárias. Com relação aos dormitórios, foram retiradas as paredes divisórias do dormitório localizado no pavimento superior do edifício 1 (Figura, 2), ficando um só vão com uma área total de $126,30 \mathrm{~m}^{2}(17,50 \mathrm{mx} 7,20 \mathrm{~m})$, com a disposição de 25 camas, para uso exclusivo dos internos maiores (SERGIPE, 1938).

Figura 9. Vista parcial do dormitório dos pensionistas maiores - Edifício 1 do Colégio Tobias Barreto (1950).

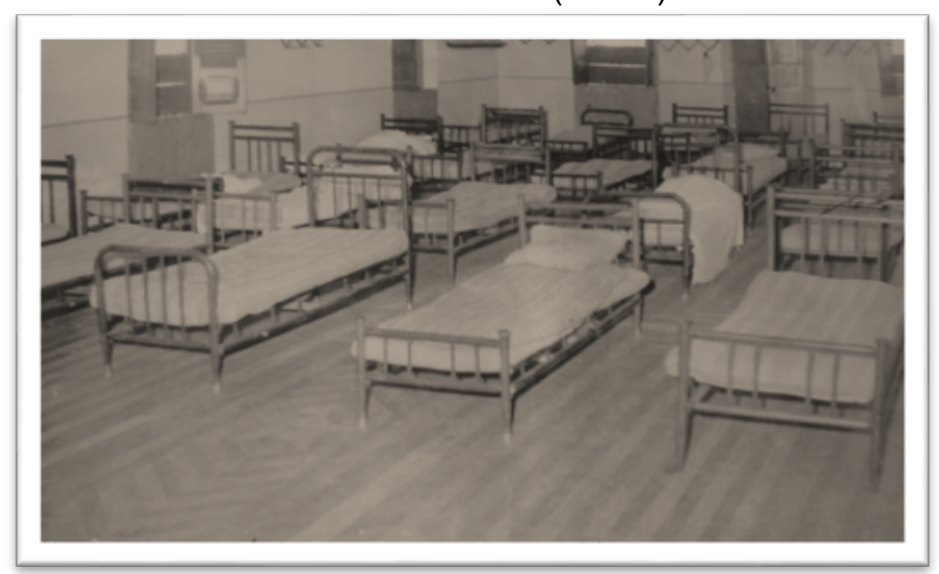

Fonte. PRATA, 1953. 
O segundo dormitório foi instalado em uma casa localizada na rua de Estância (Edifício 5) e tinha uma área total de $156,80 \mathrm{~m}^{2}$, correspondente a três pavimentos-dormitórios. No pavimento térreo ficavam as instalações sanitárias e um dormitório com $34,86 \mathrm{~m}^{2}(8,30 \times 4,20)$, com nove camas, colchões e travesseiros de capim, cabides de parede e pequenas prateleiras de madeira para depositar objetos de asseio corporal. No primeiro andar estava instalado outro dormitório com $54 \mathrm{~m}^{2}(12,4 \times 4,50)$, com a colocação de 15 camas. O terceiro pavimento (sótão) tinha uma área total de $16,80 \mathrm{~m}^{2}$ $(4,20 \times 4)$ com a colocação de quatro camas patentes. No porão dessa casa ficava instalada a rouparia. Todos os pavimentos possuíam piso assoalhado de madeira e teto forrado, exceto o sótão, que era de telha vã. As camas patentes eram guarnecidas com colchões e travesseiros de capim (SERGIPE, 1938).

A utilização dessa casa para uso de dormitório é exemplo de como um prédio construído para servir como residência, sofria improvisações em seus cômodos originais (salas, corredores, quartos, copa, cozinha, sótão, porão) para o uso de espaços de internato. Observam-se, entre outras deficiências, as camas arranjadas nos corredores, deficiência na ventilação e renovação do ar (inexistência de janelas em alguns cômodos), utilização inapropriada do sótão e porão, respectivamente como dormitório e rouparia, inexistência de instalações sanitárias em todos os pavimentos e superlotação do espaço. Portanto, as adaptações nos prédios para as dependências de internato quase sempre relegavam os preceitos de higiene às conveniências econômicas do estabelecimento. Em seguida, o esquema do prédio IV, casa de três pavimentos com as seguintes indicações: instalações sanitárias (1) e escada (2).

Figura 10. Esquema 3 - Edifício 5 do Colégio Tobias Barreto. 


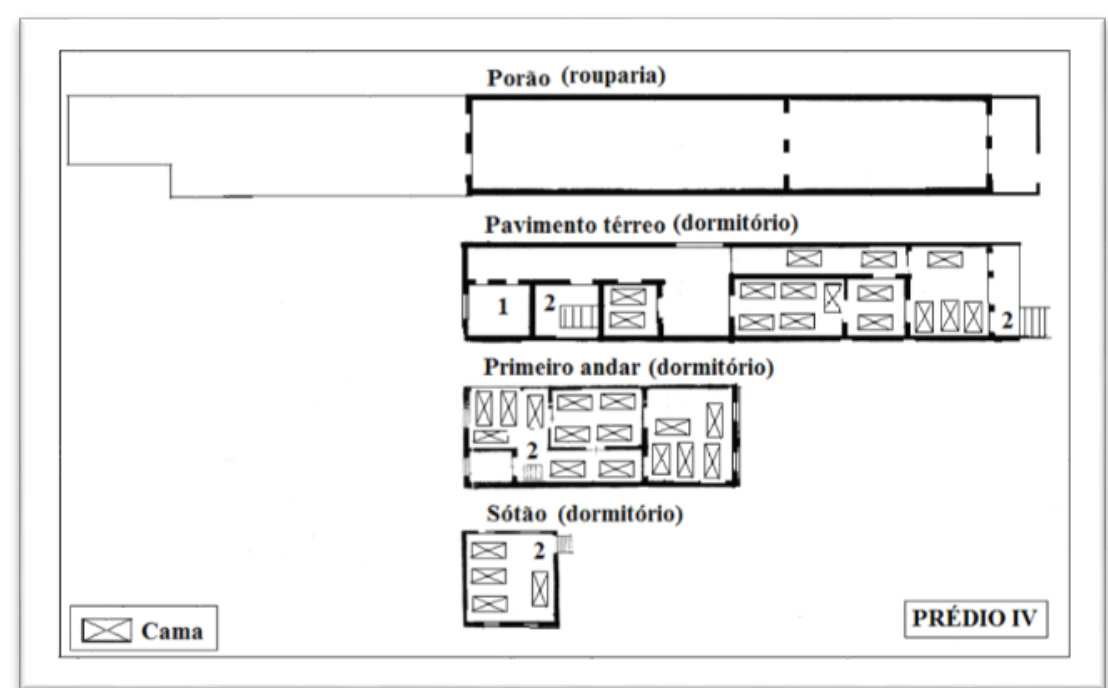

Fonte. Esquema elaborado pelo autor conforme COLÉGIO Tobias Barreto. Planta do Colégio Tobias Barreto. Planta do edifício $n^{\circ}$ 4. Aracaju, [194?]. DIES - Arquivo de Escolas Extintas.

O terceiro dormitório, privativo de alunos menores, era instalado em uma casa com a dimensão de $118,42 \mathrm{~m}^{2}$, com a disposição de 36 camas patentes providas de colchões e travesseiros de capim, e instalações e lavatórios, banheiros e sanitários contíguas aos dormitórios. O quarto dormitório ocupava duas áreas de uma casa na rua de Estância, com $83,34 \mathrm{~m}^{2}(13,10 \times 6,40)$ e a acomodação de 14 camas. O segundo e o quarto dormitórios comunicavam-se com o pavilhão central do colégio, edifício 1 , pela confluência interna das áreas descobertas (SERGIPE, 1938).

Nos dormitórios do Colégio Tobias Barreto ficava evidente um tipo de "exposição contaminadora" caracterizada pelo compartilhamento de um espaço pequeno com um grande número de pessoas, o qual ocasionava a violação do "território do eu", ou seja, "[...] a fronteira que o indivíduo estabelece entre seu ser e o ambiente é invadida, e as encarnações do eu são profanadas" (GOFFMAN, 1974). A "exposição contaminadora" ocorria pela exposição do corpo e pela relação social imposta com um grande número de pessoas. O excessivo aproveitamento do espaço tornava o ambiente insalubre e ensejava a promiscuidade entre os internos, apesar da contínua vigilância. No entanto, por questões de economicidade, as improvisações e/ou superlotação foram dominantes nos colégios-internatos (CONCEIÇÃO, 2012a). 
O refeitório também, também era marcado por improvisações. Assim, funcionava improvisado na ala lateral (alpendre) no fundo do prédio 2 , com uma área de $81,12 \mathrm{~m}^{2}(20,28 \mathrm{x} 4 \mathrm{~m})$.

Figura 11. Vista parcial do refeitório do Colégio Tobias Barreto (Edificio 2).

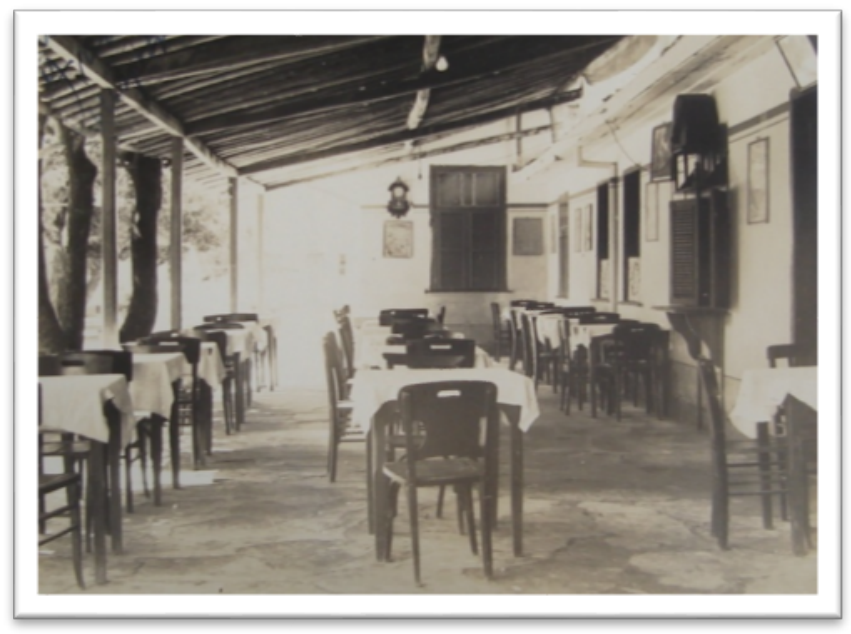

Fonte. SOUZA, 1935.

E, no esquema apresentado em seguida podem ser observadas as adaptações no prédio 2 , principalmente com a improvisação do refeitório na varanda do respectivo prédio. Os números representam os seguintes ambientes: sala de aula (1), sala de ciências naturais (2), sala de demonstração (3), arquivo (4), gabinete de física, química e história natural (5), banheiro e sanitário (6), cozinha (7), copa (8), despensa (9), abrigo para recreio (10) e refeitório (11).

Figura 12. Esquema 4 - Edificio 2 do Colégio Tobias Barreto.

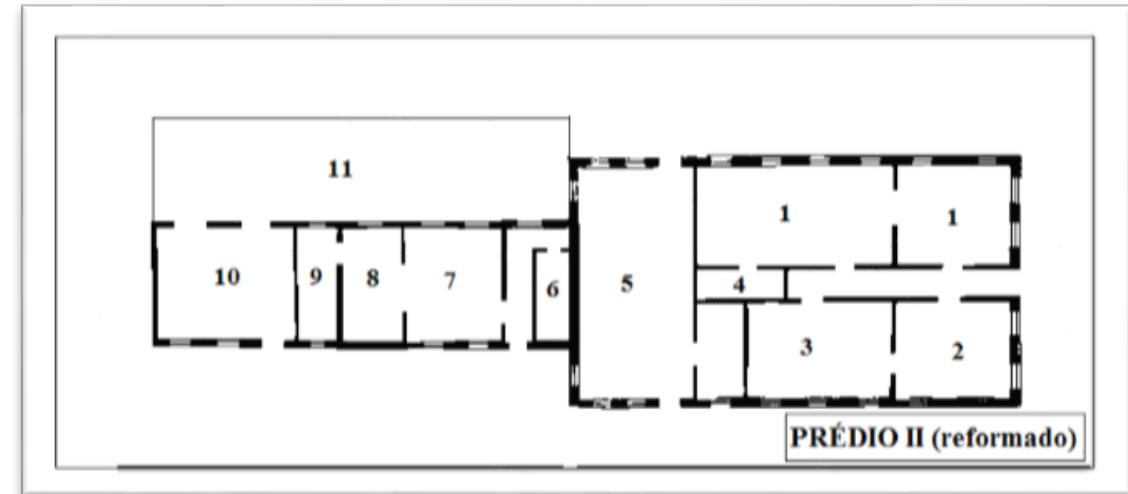

Fonte. Esquema elaborado pelo autor conforme GINÁSIO Tobias Barreto. Planta do edifício $\mathbf{n}^{\circ} \mathbf{2}$ do Ginásio Tobias Barreto. Aracaju, [194?]. DIES - Arquivo de Escolas Extintas. 
O internato do Colégio Tobias Barreto dispunha de duas rouparias improvisadas: uma era localizada no porão do edifício 5 , destinada aos alunos maiores e médios, com uma área de $117 \mathrm{~m}^{2}(26 \times 4,50)$, e a outra, com $12,21 \mathrm{~m}^{2}$, servia ao dormitório dos menores, dispondo de armários coletivos para roupas. Quanto ao serviço de lavanderia, o estabelecimento providenciava a lavagem de toda a roupa de cama e mesa e vestuário fora do estabelecimento.

No final da década de 1940 eram seis casas, contíguas ou próximas umas das outras, em que o estabelecimento distribuía as diversas dependências do internato. $O$ esquema em sequência apresenta a disposição dessas casas ocupadas por instalações do internato do Colégio Tobias Barreto.

Figura 13. Esquema 5 - Situação espacial dos prédios do Colégio Tobias Barreto (1950).

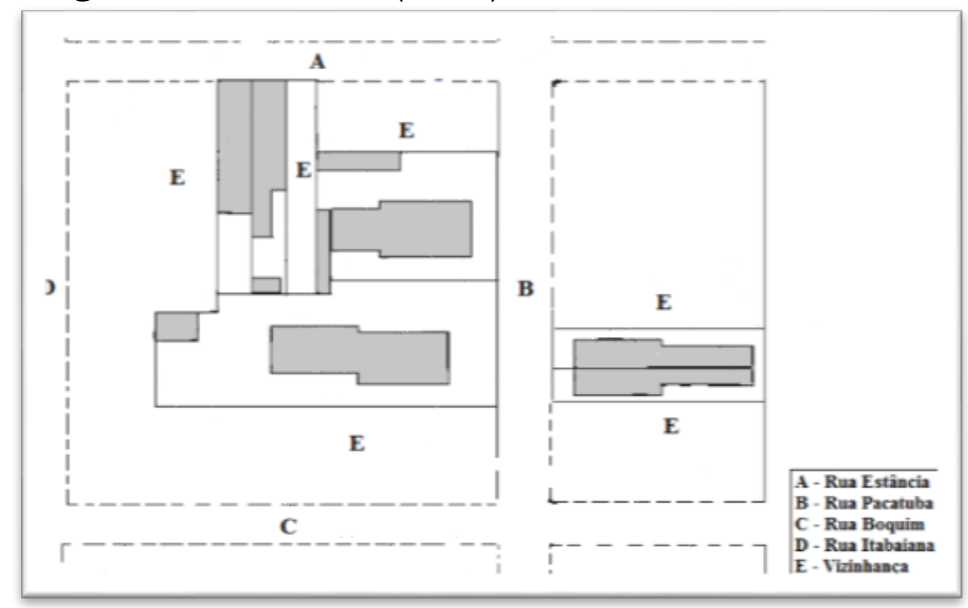

Fonte. Esquema elaborado pelo autor conforme COLÉGIO Tobias Barreto. Planta da situação do Colégio Tobias Barreto. Aracaju, DIES - Arquivo de Escolas Extintas, [194?].

Diferentemente do que ocorreu com colégios católicos instalados em Sergipe, que conseguiram construir prédios originalmente projetados para servirem como estabelecimentos escolares, o Colégio Tobias Barreto sempre funcionou em casas e/ou sobrados antigos, com adaptações para servirem como colégios-internatos. Os arranjos nem sempre conseguiram acordo com as recomendações higiênicas que circulavam na época. Apesar disso, as inspeções acabavam por aprovar as condições físicas do colégio. 


\section{Espaço projetado: o edificio-internato do Colégio Nossa Senhora de Lourdes}

O Colégio Nossa Senhora de Lourdes foi fundado em Aracaju no ano de 1903 (COLÉGIO, 1941), pela Congregação das Religiosas do Santíssimo Sacramento, e oferecia instrução feminina, em regime de internato, semiinternato e externato. Inicialmente, o estabelecimento ministrava apenas o curso primário. Ao longo das décadas de 1930 e 1940 obteve autorização para oferecer o curso de formação para o magistério e o curso ginasial (primeiro ciclo do ensino secundário), ampliando a clientela atendida pelo estabelecimento. A formação das meninas e moças entregues aos cuidados das Irmãs Sacramentinas era, como de costume nos colégios femininos, complementada pela instrução das prendas domésticas (costura, bordados), bandolim, piano, desenho (COSTA, 2003). Estes conteúdos objetivavam a preparação da mulher para assumir seu papel social de esposa e mãe, conforme a cultura da época (PASSOS, 1995; CONCEIÇÃO, 2012b).

O Colégio N. Sra. de Lourdes funcionou em casa residencial com adaptações até 1925, ano em que foi inaugurado o edifício-internato da instituição. O prédio desse colégio foi o primeiro edifício originalmente projetado e construído para servir às funções de colégio-internato. O prédio, que passou por modificações e ampliações ao longo do tempo, quando totalmente finalizado, contava com três pavilhões e uma capela anexa, e tinha capacidade para mais de 600 alunas na condição de externas, internas e semi-internas em dois turnos de funcionamento (SERGIPE, 1953). O edificio possuía as principais divisões indicadas para o funcionamento de um internato (ALENCAR, 1945), como dormitórios, refeitório, cozinha, despensa, rouparia e instalações sanitárias, permitindo o recebimento de mais ou menos 80 alunas na condição de pensionistas.

A fachada principal do edifício-internato do Colégio N. Sra. de Lourdes (Figura 14), localizada na Rua João Pessoa - centro da capital Aracaju, foi disposta para o leste, considerada mais conveniente sob o aspecto higiênico (MELLO, 1912), pois essa disposição permite que o sol banhe a face do edifício logo às primeiras horas da manhã, estendendo esse efeito até pouco 
depois do meio-dia, evitando a umidade indesejável facilitadora da proliferação de doenças (SOUTO, 1946).

Figura 14. Fachada do Colégio Nossa Senhora de Lourdes (1951).

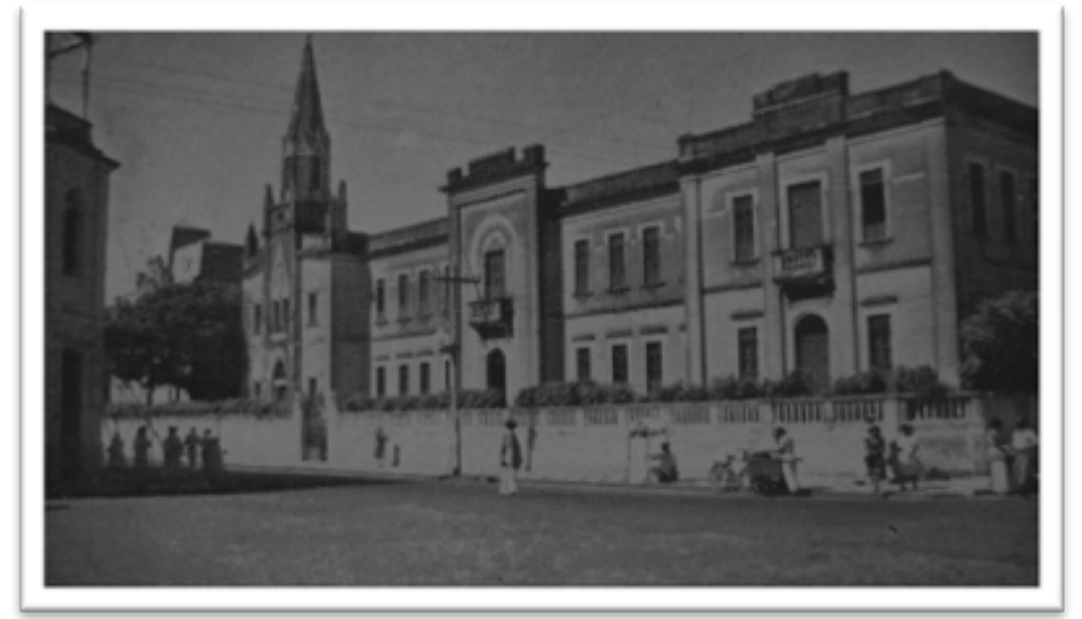

Fonte. BRASIL. Instituto Brasileiro de Geografia e Estatística. Sinopse Estatistica do Municipio de Aracaju.

Rio de Janeiro: IBGE, 1951.

Segundo relatórios de inspeções realizadas na década de 1930, a posição espacial do edificio era saudável, isento de poeira, não havendo depósito de lixo nem emanações fétidas ou águas estagnadas nas suas proximidades. A ausência de ruídos, embora o prédio estivesse localizado em uma área de comércio, era garantida pelo fato de ter sido construído completamente isolado dos prédios fronteiriços. Além disso, ao longo das décadas seguintes, foram providenciados outros acessos para as alunas pelas ruas laterais.

Em linhas gerais, o edifício do Colégio N. S. de Lourdes seguia o plano arquitetônico com a disposição de fachada principal separada da rua por um espaço de jardim e um muro em toda sua extensão. Contava com dois pavimentos, uma capela anexa e um grande pátio interno que facilitava a penetração da luminosidade e da ventilação. Na entrada do prédio ficavam localizadas a sala de espera e a sala de visitas, ambientes que separavam pessoas estranhas do contato com as dependências internas do colégio. Este modelo seguia traços típicos de colégios confessionais católicos que procuravam resguardar o interior do estabelecimento e estabelecia a separação entre os espaços de uso administrativo, pedagógico e do internato (CONCEIÇÃO, 2012). 
No pavimento térreo, os espaços específicos do internato eram o refeitório, a copa, a cozinha, a dispensa e a lavanderia, localizados nos pavilhões I e II. Em todos esses ambientes adotou-se a recomendação higiênica da colocação de piso de ladrilho e revestimento das paredes com azulejo, para facilitar o asseio diário, e a disposição de janelas para iluminação e renovação do ar (RIBEIRO, 1997). O refeitório estava instalado em sala ampla, com a colocação de grandes mesas com capacidade para mais ou menos 10 internas. A cozinha era provida de fogão à lenha, duas pias, instalação de água quente e fria, armários e depósitos de detritos. A despensa era um compartimento com armários onde os gêneros alimentícios eram conservados e guardados em latas.

No esquema do pavimento térreo, apresentado na figura 15 , podem ser observadas a situação posicional do prédio, as divisões internas e a funcionalidade do projeto: sacristia (1), capela (2), sala das vocações sacerdotais (3), quarto (4), sala de visitas (5), sala de espera (6), hall (7), escada (8), sala da inspetoria (9), corredor (10), sala de comunidade (11), gabinete físico biométrico, sala de aula (12), sala de aula (13), refeitório das alunas (14), refeitório das irmãs (15), cozinha (16), dispensa (17), gabinete de história natural (18), gabinete de fisica e química (19), varanda (20), sala de geografia (21), recreio (22), instalações sanitárias (23) e lavanderia (24).

Figura 15. Esquema do pavimento térreo - Colégio N. Sra. de Lourdes

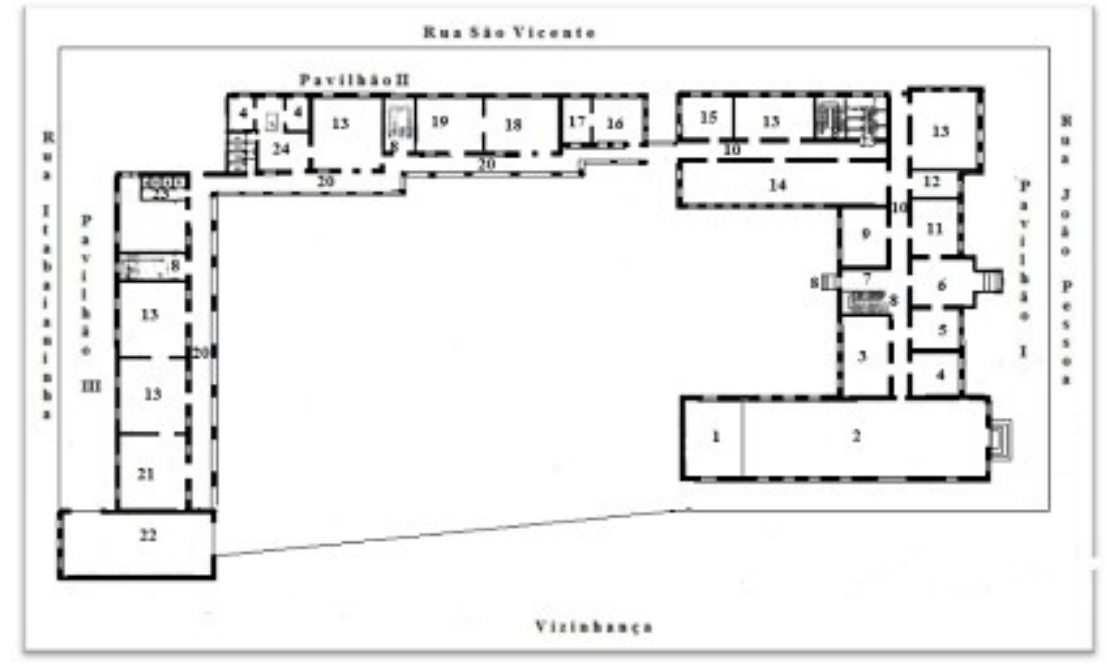


Fonte. LEITE, José Rolemberg. Planta baixa do Colégio Nossa Senhora de Lourdes. Pavimento térreo. Aracaju, [192?]. DIES - Arquivo de Escolas Extintas.

No pavimento superior, nos pavilhões I e II, estavam instalados os dormitórios das alunas, quarto das irmãs, rouparia e instalações sanitárias. No pavilhão III e parte do II estavam dispostas diversas salas de aulas e o salão de conferências. A alocação dos dormitórios no pavimento superior era uma organização típica dos edifícios-internatos construídos com pavimentos superiores e procurava garantir, sobretudo nos internatos femininos, separação da parte íntima do internato (dormitórios) das atividades escolares e do contato imediato com os acessos do prédio ao mundo exterior. A figura 16, apresenta a disposição dos cômodos existentes no pavimento superior do Colégio N. Sra. de Lourdes: sala de aula (1), capela (2), coro (3), quarto (4), quarto das irmãs (5), dormitório (6), rouparia (7), corredor (8), instalações sanitárias (9), salão de conferências (10), escada (11) e varanda (12).

Figura 16. Esquema do pavimento superior - Colégio N. Sra. de Lourdes.

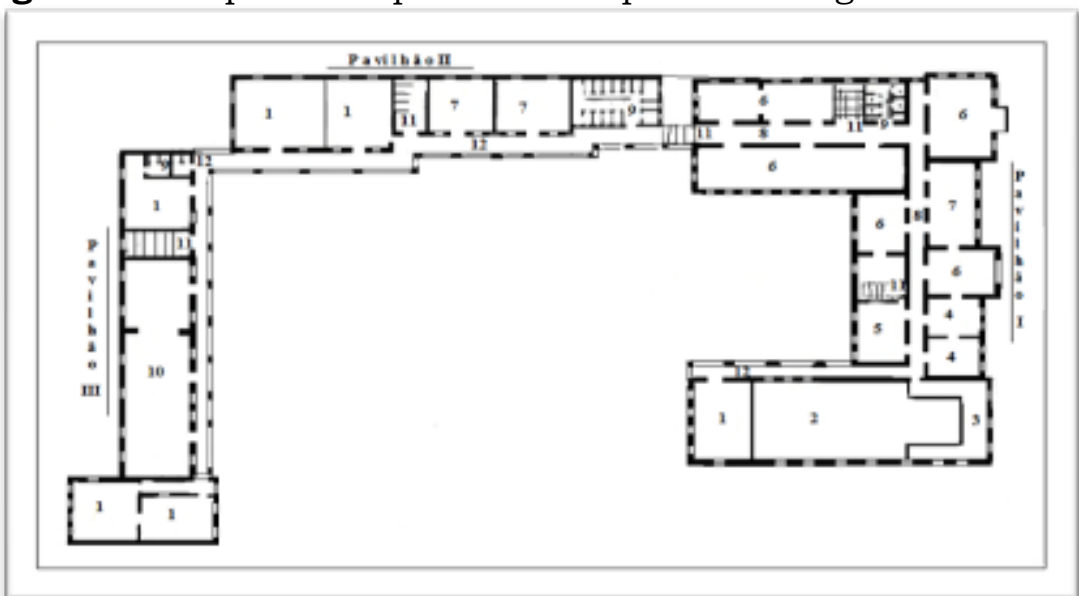

Fonte. LEITE, José Rolemberg. Planta baixa do Colégio Nossa Senhora de Lourdes. Pavimento superior. Aracaju, [192-?]. DIES Arquivo de Escolas Extintas.

O edifício-internato do Colégio N. Sra. de Lourdes possuía cinco dormitórios que seguiam o modelo de quartos e/ou salões, sem divisões internas ou divisórias, guarnecidos por camas de ferro com lastro de mola (modelo patente). Em certos colégios femininos católicos, nos dormitórios coletivos ou grandes salões as camas das internas eram isoladas uma das outras através de cortinas e/ou divisórias internas de madeira de meia altura (PASSOS, 1995). No internato do Colégio N. Sra. de Lourdes a opção 
pela disposição de vários dormitórios, embora pudesse dificultar a vigilância realizada pelas irmãs religiosas, foi utilizada para fazer a separação das internas de acordo com a idade e desenvolvimento. Os dormitórios possuíam as seguintes dimensões: $36,54 m^{2}-38,54 m^{2}-71 m^{2}-80,56 m^{2}-121 m^{2}$, perfazendo um total de $347,64 \mathrm{~m}^{2}$ de área exclusiva para dormitório. A lotação dos dormitórios chegou a 74 leitos nos primeiros anos, ficando em desacordo com a legislação sanitária da época, que determinava a superfície mínima de $6 \mathrm{~m}^{2}$ por pessoa ou leito (SERGIPE, 1937). Contudo, respeitava a superfície mínima de $4,50 \mathrm{~m}^{2}$ do dormitório para cada interno, defendida por higienistas, condicionada a um sistema suficiente de circulação e renovação constante do ar e uma boa cubagem do dormitório. Estas situações eram atendidas pelos dormitórios do Colégio N. Sra. de Lourdes, visto que os mesmos eram guarnecidos de grande quantidade de janelas e um pé direito com altura de mais ou menos $4,47 \mathrm{~m}$, o que permitia uma boa cubagem. No pavimento superior também existiam três salas que serviam como rouparia, lavatórios, sanitários, banheiros com divisões internas para os vasos sanitários e os chuveiros. Em todos esses espaços também se observou o cuidado higiênico na colocação de ladrilhados no piso e revestimento das paredes com azulejos até a altura de $1,60 \mathrm{~m}$.

Os espaços de uso das alunas pensionistas não se confundiam com os utilizados pelas irmãs. $\mathrm{Na}$ arquitetura do prédio existiam quartos e refeitório para o uso exclusivo das religiosas. Mas teve-se o cuidado de alocar os aposentos das irmãs próximo ao das internas possibilitando a vigilância e os cuidados com estas. Esse modelo de prédio escolar inaugurado em Sergipe pelas Irmãs do Santíssimo Sacramento, com a fundação do Colégio N. Sra. de Lourdes, representou a concretização do ideal higiênico pedagógico (RIBEIRO, 1997) de um edifício especialmente projetado e construído para o funcionamento de colégio-internato.

\section{Considerações finais}

Em Sergipe, na primeira metade do século XX, somaram-se aos pequenos internatos de organização "familiar" colégios-internatos caracterizados pela existência de espaços específicos para internato, ainda 
que adaptados, por um conjunto de empregados encarregados dos serviços e pelo aumento dos alunos pensionistas. Esses internatos estavam instalados na capital do Estado e nas sedes dos municipios mais desenvolvidos. Aracaju, por sua condição de capital, congregava internatos maiores, mais renomados, dispondo inclusive do ensino secundário e por essas razões mais requisitados pelas famílias ricas.

Nas primeiras décadas do século XX, contando com o apoio da Igreja e do Estado, cresceram e se desenvolveram colégios dirigidos por congregações católicas e com eles os primeiros edificios construídos originalmente para funcionar como colégio-internato. O prédio do Colégio N. Sra. de Lourdes foi o primeiro edificio originalmente projetado e construído para servir às funções de colégio-internato feminino. O edificio, construído em dois pavimentos, possuía as principais divisões indicadas para o funcionamento de um internato (dormitórios, refeitório, rouparia, instalações sanitárias, cozinha, copa, despensa). Esse modelo de prédio escolar inaugurado em Sergipe pelas Irmãs do Santíssimo Sacramento, com a fundação do Colégio N. S. de Lourdes, representou a concretização do ideal higiênico pedagógico de um edificio especialmente projetado e construído para o funcionamento de colégio-internato.

Destacaram-se os internatos dos estabelecimentos não-confessionais, Tobias Barreto, Grêmio Escolar e Jackson de Figueiredo, estabelecidos em Aracaju. Embora congregassem muitos alunos pensionistas, o espaço do internato e todas as dependências desses estabelecimentos resultaram de adaptações em prédios assobradados.

O Colégio Tobias Barreto é exemplo de internato funcionando em espaços adaptados. O colégio ocupou casas e/ou sobrados residenciais alugados, de construção antiga, localizados em diferentes pontos no centro da cidade. As instalações para os serviços do internato (dormitórios, refeitório, rouparia e instalações sanitárias) estavam adaptadas em diferentes espaços de um conjunto de casas ocupadas pelo colégio. Essas casas e/ou sobrados antigos foram construídos, originalmente, para residência familiar, e mesmo as modificações visando à adaptação dos 
prédios para a finalidade escolar não lhes modificaram substancialmente o destino original de residência.

As adaptações de cômodos de prédios residenciais, ocupados pelo Colégio Tobias Barreto, para servirem às necessidades de um internato, apresentavam algumas deficiências. Podem ser indicadas, entre outras, as camas arrumadas nos corredores, deficiência na ventilação e renovação do ar (inexistência de janelas em alguns cômodos), utilização inapropriada de certos cômodos (sótão e porão) como dormitório, rouparia, inexistência de instalações sanitárias em todos os pavimentos e superlotação do espaço. Assim, as adaptações nos prédios para as dependências de internato quase sempre relegavam os preceitos de higiene às conveniências econômicas do estabelecimento.

\section{Referências e fontes}

ALENCAR Neto, Meton. Edificios escolares para internatos. Revista Brasileira de Estudos Pedagógicos, Rio de Janeiro, v. 6, n. 18, p. 393-405, dez. 1945. AMADO, Gilberto. História da minha infância. São Cristóvão: UFS, 1999.

Bencostta, Marcus Levy. A escrita da arquitetura escolar na historiografia da educação brasileira (1999-2018). Revista Brasileira de História da Educação, 19. DOI: http://dx.doi.org/10.4025/rbhe.v19.2019.e064

BRASIL. Instituto Brasileiro de Geografia e Estatística. Sinopse Estatística do Municipio de Aracaju. Rio de Janeiro: IBGE, 1951.

COLÉGIO N. S. de Lourdes. Estatutos do Colégio N. S. de Lourdes, 12 de setembro de 1941. Aracaju, 1941. DIES - Arquivo de Escolas Extintas.

COLÉGIO Tobias Barreto. Planta da situação do Colégio Tobias Barreto. Aracaju, [194?]. DIES - Arquivo de Escolas Extintas, [194?].

COLÉGIO Tobias Barreto. Planta do Colégio Tobias Barreto. Prédios 1 e 2. Aracaju, DIES - Arquivo de Escolas Extintas, [193?].

CONCEIÇÃO, Joaquim Tavares da. Internar para educar. Colégios-internatos no Brasil (1840-1950). Tese (Doutorado em História) - Faculdade de Filosofia e Ciências Humanas, Universidade Federal da Bahia, Bahia. 2012b.

COSTA, Rosemeire Marcedo. Fé, civilidade e ilustração: as memórias de exalunas do Colégio Nossa Senhora de Lourdes (1903-1973). 2003. Dissertação Interfaces da Educ., Paranaíba, v.11, n.31, p. 68-92, 2020 
(Mestrado em Educação) - Universidade Federal de Sergipe, São Cristóvão, SE, 2003.

FREIRE, M. Franco. Relatório relativo às verificações necessárias à concessão de inspeção preliminar ao Colégio Tobias Barreto, 22 de janeiro de 1933. Aracaju. DIES - Arquivo de Escolas Extintas, 1933.

GINÁSIO Tobias Barreto. Planta do edifício $n^{\circ} 2$ do Ginásio Tobias Barreto. Aracaju, [194?]. DIES - Arquivo de Escolas Extintas, [194?].

GOFFMAN, Erving. Manicômios, prisões e conventos. São Paulo: Perspectiva, 1974.

GUIMARÃES, Ophelia. Relatório da inspeção permanente do Colégio Tobias Barreto, 3 de Janeiro de 1936. Rio de Janeiro. Aracaju. DIES - Arquivo de Escolas Extintas, 1936.

LEITE, José Rolemberg. Planta baixa do Colégio Nossa Senhora de Lourdes. Aracaju, [192-?]. DIES - Arquivo de Escolas Extintas.

MANGUEIRA, Francisco Igor de Oliveira. Colégio Tobias Barreto: escola ou quartel? (1909-1946). 2003. Dissertação (Mestrado em Educação) Universidade Federal de Sergipe, São Cristóvão, SE, 2003.

MELLO, B. Vieira. Requisitos para um bom internato. São Paulo: Weiszflog Irmãos, 1912.

PASSOS, Elizete Silva. A educação das virgens. Um estudo do cotidiano do Colégio Nossa Senhora das Mercês. Rio de Janeiro: Editora Universitária Santa Úrsula, 1995.

PRATA, Hernane Mesquita. Relatório da Inspetoria Federal do Ginásio Tobias Barreto,14 de janeiro de 1953. Aracaju, DIES - Arquivo de Escolas Extintas, 1953.

RIBEIRO, Eurico Branco. A higiene nos internatos: Estudo das condições sanitárias dos internatos de São Paulo. In: COSTA, Maria José Franco Ferreira da; SHENA; Denílson Roberto; SCHMIT; Maria Auxiliadora. (Org.). I Conferência Nacional de Educação. Brasília: SEDEIA/ INEP/ IPARDES, 1997. SAMPAIO, Arnaldo de Almeida. Inspetoria Federal do Ginásio Tobias Barreto. Elucidativo para ficha de classificação, 21 de outubro de 1946. Aracaju. DIES - Arquivo de Escolas Extintas, 1946. 
SANTANA, José Cabral. Relatório para revisão da ficha de classificação do Ginásio Tobias Barreto, 21 de julho de 1943. Aracaju - Arquivo de Escolas Extinta, 1943.

SANTOS, Magno Francisco de Jesus. Ecos da modernidade. A arquitetura dos grupos escolares sergipanos (1911-1926). São Cristóvão: UFS, 2013.

SERGIPE. Decreto $\mathrm{n}^{\circ} 77$, de 24 de maio de 1937. Dá regulamento ao Departamento de Saúde Pública do Estado de Sergipe. 1937.

SERGIPE. Inspetoria Federal do Ginásio N. Sra. de Lourdes. Relatório de Verificação Prévia. Aracaju, 1953. DIES - Arquivo de Escolas Extintas.

SERGIPE. Inspetoria Federal. Relatório de inspeção preliminar do Colégio Tobias Barreto. Aracaju. DIES - Arquivo de Escolas Extintas, 1938.

SERGIPE. Termo de Visita. Colégio N. S. da Conceição, 8 de abril de 1927. Arquivo Público de Sergipe, 1927.

SOUTO, Valois. A tuberculose entre os escolares. Revista Brasileira de Estudos Pedagógicos, Rio de Janeiro, v. 7, n. 20, p. 241-248, fev. 1946.

SOUZA, José Machado de; TAVARES, João Maria; MELO, Otaviano Vieira de. Relatório Inspetoria Federal do Colégio Tobias Barreto, em 27 de novembro de 1935. Aracaju, DIES - Arquivo de Escolas Extintas. 1935.

VIÑAO FRAGO, Antonio; ESCOLANO, Agustín. Currículo, espaço e subjetividade: a arquitetura como programa. Trad. Alfredo Veiga Neto. Rio de Janeiro: DP\&A, 1998. 